Preventive Care in Nursing and Midwifery Journal

2020; 10(1): 56-61

\title{
The Effect of Endurance Training and Coenzyme Q10 Supplementation on Sleep Quality in Children With Autism Spectrum Disorders
}

\author{
Ahmadi $\mathrm{S}^{1}{ }^{10}, \underline{\text { Aghvamy }}^{\mathrm{MS}^{2 *}}{ }^{*}$, Afshinjoo $\mathrm{M}^{2} \mathbb{D}$ \\ ${ }^{1}$ Cultural \& student department, Zanjan university of medical sciences, Zanjan ,Iran \\ ${ }^{* 2}$ Nursing and Midwifery faculty, Zanjan university of medical sciences, Zanjan, Iran
}

*Corresponding Author Adress: Zanjan university of medical sciences \& health, Nursing and Midwifery faculty, Mahdavi st, Zanjan, Iran

Tel: 0098-9127721858

Email: aghvamym@yahoo.com

Received: 2 Dec 2019

Accepted: 28 Oct 2020

\begin{abstract}
Background: Autism is a developmental disorder that impairs social relationships. Sleep disorders are one of the major problems of patients with autism spectrum disorders (ASD).

Objectives: Concerning the need to investigate problems and impairments caused by this disease, the present study aimed at determining the effect of an eight-week endurance training program plus Q10 supplementation on sleep quality in children with ASD in 2017.

Methods: The present double-blind study was performed on three experimental groups. Group 1 performed eight-week endurance training on a one-mile distance as brisk walking. Group 2 received $100 \mathrm{mg}$ Q10 supplements daily and Group 3 underwent a combination of both interventions. Pre- and post-tests were performed to determine the sleep habits of the study subjects using the children's sleep habits questionnaire (CSHQ) by parents. Finally, the pre- and post-tests data were compared using the paired samples t-test.

Results: A significant difference was observed between the pre- and post-test results in the mean total and eight subscales scores in the endurance training plus Q10 supplementation group $(\mathrm{P}<0.05)$. There was no significant difference between the pre- and post-test results in the sleep anxiety and sleep-disordered breathing subscales in the endurance training group and the sleep-disordered breathing subscale in the supplementation group.
\end{abstract}

Conclusion: According to the study results, it seems that the sleep of children with autism was improved by increased physical activity and Q10 supplementation.

Keywords: endurance training, coenzyme q10, sleep quality, autism

\section{Introduction}

Autism spectrum disorders (ASD) is a developmental disorder of the nervous system, which its major manifestations are impaired social interactions, repetitive behaviors and motor skills delay, including delayed sitting, crawling, walking, as well as altered gait, abnormal posture control, and poor motor planning [1,2]. The prevalence of ASD is 1 in 42 for males and 1 in
189 for females; i e, four times higher in males than females $[3,4]$. The prevalence of ASD in the United States was 4-5 per 1000 in 1990, 1 in 150 in 2007, 1 in 91 in 2009, and 1 in 50 in 2013 [5]. According to the World Health Organization (WHO) report, the approximate prevalence of ASD in 2014 was $2.24 \%$, about three times higher than that of 2000; this increasing trend led to numerous researches in recent decades [6,7] and 
identification of the causes of autism in order to achieve better treatment was on top of the topics [7].

The results showed that early behavioral interventions are a useful and effective treatment for ASD [8], which one of the most important ones is motor skills in physical activity, and endurance exercises, including boating competitions (about six minutes), marathon race (about 2-3 hours), and even some cycling competitions (about four hours). Such activities often are the sources of ATP production in the aerobic system, in which the duration of the event is the only difference [9]. Different studies emphasized the effect of endurance training on the sleep quality of children with ASD and reported the role of physical activity and exercise in the sleep improvement of such children [10-12].

Besides sleep disorder in children with ASD, impairment of energy metabolism is also observed in some cases [13]. Coenzyme Q10 (CoQ10) is an essential component for the electron-transport chain that speeds up the mitochondrial metabolism, releasing bioenergy in various tissue, especially skeletal muscles. Some researchers believe that exogenous consumption to improve plasma or tissue levels by taking Q10 supplements can prevent stress or adverse changes in some biochemical parameters caused by energy loss during exercise $[14,15]$. CoQ10 is synthesized from the amino acid tyrosine in all body cells, especially the heart, liver, kidneys, and pancreas, and plays a pivotal role in their intracellular energy production. Therefore, the present study aimed at determining the effect of an eight-week endurance training and Q10 supplementation on the sleep quality of children with ASD in 2016.

\section{Methods}

The present quasi-experimental study with a double-blind design and pre- and post-tests was performed on three experimental groups. The subjects were selected by the convenience sampling method. The three groups underwent an eight-week intervention as endurance training, Q10 supplementation, and a combination of both interventions, separately. Sleep habits were determined in all three groups as a pre-test. The groups were also homogenized for some demographic characteristics and physical indicators.

The statistical population included all children aged 4-11 years with ASD under the supervision of the Department of Cooperatives, Labour, and Social Welfare of Zanjan, from which 21 subjects were purposefully selected and assigned into three intervention groups. The children's sleep habits questionnaire (CSHQ) was utilized to determine the sleep quality of the participants. The CSHQ was developed by Owens [16] to assess the sleep habits of children aged 4-11 years and includes eight subscales of bedtime resistance, sleep-onset delay, sleep duration, sleep anxiety, night waking, parasomnias, sleep-disordered breathing, and daytime sleepiness. The CSHQ is scored based on a three-point Likert scale (always, sometimes, never); scores above average correspond to more disturbed sleep and scores below average to healthy sleep habits.

In the present study, the content validity method was used to evaluate the validity of the instrument, and Cronbach's alpha coefficient to assess its reliability that was 0.81 . Group 1 underwent an eight-week endurance training program on a one-mile distance as brisk walking. Group 2 received $50 \mathrm{mg}$ Q10 twice a day (11:00 am and 6:00 pm), totally $100 \mathrm{mg}$, under the supervision of a sports nutritionist, and their behavioral changes were evaluated by asking their parents. Group 3 underwent a combination of endurance training and Q10 supplementation. Sleep habits of the participants were evaluated by CSHQ completed by the parents twice as pre-and post-tests. Then the pre- and post-test results of the three groups were compared to determine the effect of endurance training, Q10 supplementation, and a combined intervention on the sleep quality of the subjects. Descriptive statistics were used to classify and assess the data distribution of demographic characteristics, and the Shapiro-Wilk test was used to determine the normality in the data distribution. The paired samples t-test was utilized to test the research hypotheses. Data were analyzed using SPSS version 24.

\section{Results}

In the present study, 21 children with ASD aged $9.52 \pm 5.46$ years, BMI of $15.85 \pm 4.78 \mathrm{~kg} / \mathrm{m} 2$, and 
endurance exercises of $92.22 \pm 8.25$ minutes per week participated (seven in each group).

In the endurance training group, the mean scores of total CSHQ and its eight subscales decreased in the post-test, after the intervention. However, the difference was insignificant in sleep anxiety and sleep-disordered breathing (Table 1).

Table 1: Comparison of the mean $( \pm S D)$ pre- and pre-test scores of CSHQ in the endurance training group

\begin{tabular}{|c|c|c|c|c|c|}
\hline Variable & Test & Mean & Standard Deviation & $\mathbf{t}$ & P value \\
\hline \multirow{2}{*}{ Total } & Pre-test & 56.67 & 7.02 & \multirow{2}{*}{4.112} & \multirow{2}{*}{$* 0.001$} \\
\hline & Post-test & 46.23 & 8.02 & & \\
\hline \multirow{2}{*}{ Lack of sleep } & Pre-test & 14.12 & 4.21 & \multirow{2}{*}{3.15} & \multirow{2}{*}{$* 0.001$} \\
\hline & Post-test & 12.02 & 3.21 & & \\
\hline \multirow{2}{*}{ Bedtime resistance } & Pre-test & 9.26 & 1.92 & \multirow{2}{*}{3.04} & \multirow{2}{*}{$* 0.001$} \\
\hline & Post-test & 7.26 & 2.25 & & \\
\hline \multirow{2}{*}{ Parasomnia } & Pre-test & 9.91 & 3.08 & \multirow{2}{*}{2.56} & \multirow{2}{*}{$* 0.001$} \\
\hline & Post-test & 8.87 & 2.08 & & \\
\hline \multirow{2}{*}{ Sleep anxiety } & Pre-test & 5.56 & 2.18 & \multirow{2}{*}{1.71} & \multirow{2}{*}{0.356} \\
\hline & Post-test & 5.02 & 2.12 & & \\
\hline \multirow{2}{*}{$\begin{array}{c}\text { Inadequate sleep } \\
\text { duration }\end{array}$} & Pre-test & 6.06 & 1.12 & \multirow{2}{*}{2.68} & \multirow{2}{*}{$* 0.001$} \\
\hline & Post-test & 4.66 & 1.00 & & \\
\hline \multirow{2}{*}{ Night waking } & Pre-test & 4.52 & 2.08 & \multirow{2}{*}{2.98} & \multirow{2}{*}{$* 0.001$} \\
\hline & Post-test & 3.36 & 2.78 & & \\
\hline \multirow{2}{*}{$\begin{array}{l}\text { Sleep-disordered } \\
\text { breathing }\end{array}$} & Pre-test & 4.93 & 1.56 & \multirow{2}{*}{1.08} & \multirow{2}{*}{0.292} \\
\hline & Post-test & 4.03 & 1.13 & & \\
\hline \multirow{2}{*}{ Sleep onset delay } & Pre-test & 2.13 & 2.08 & \multirow{2}{*}{2.54} & \multirow{2}{*}{$* 0.001$} \\
\hline & Post-test & 1.01 & 2.38 & & \\
\hline
\end{tabular}

In the Q10 supplementation group, the mean scores of total CSHQ and its eight subscales decreased in the post-test, after the intervention.
However, the difference was insignificant in sleep-disordered breathing (Table 2).

Table 2: Comparison of the mean ( \pm SD) pre- and pre-test scores of CSHQ in the Q10 supplementation group

\begin{tabular}{|c|c|c|c|c|c|}
\hline Variable & Test & Mean & Standard Deviation & $\mathbf{t}$ & P value \\
\hline \multirow{2}{*}{ Total } & Pre-test & 56.71 & 8.56 & \multirow{2}{*}{3.56} & \multirow{2}{*}{$* 0.001$} \\
\hline & Post-test & 47.10 & 8.91 & & \\
\hline \multirow{2}{*}{ Lack of sleep } & Pre-test & 14.32 & 3.12 & \multirow{2}{*}{3.36} & \multirow{2}{*}{$* 0.001$} \\
\hline & Post-test & 13.02 & 3.21 & & \\
\hline \multirow{2}{*}{ Bedtime resistance } & Pre-test & 9.91 & 2.36 & \multirow{2}{*}{3.00} & \multirow{2}{*}{$* 0.001$} \\
\hline & Post-test & 8.26 & 2.25 & & \\
\hline \multirow{2}{*}{ Parasomnia } & Pre-test & 9.89 & 2.00 & \multirow{2}{*}{2.12} & \multirow{2}{*}{$* 0.001$} \\
\hline & Post-test & 8.96 & 2.08 & & \\
\hline \multirow{2}{*}{ Sleep anxiety } & Pre-test & 5.03 & 2.02 & \multirow{2}{*}{1.98} & \multirow{2}{*}{0.046} \\
\hline & Post-test & 4.02 & 2.12 & & \\
\hline \multirow{2}{*}{$\begin{array}{l}\text { Inadequate sleep } \\
\text { duration }\end{array}$} & Pre-test & 6.06 & 1.03 & \multirow{2}{*}{2.46} & \multirow{2}{*}{$* 0.001$} \\
\hline & Post-test & 4.06 & 1.00 & & \\
\hline \multirow{2}{*}{ Night waking } & Pre-test & 4.56 & 2.71 & \multirow{2}{*}{2.09} & \multirow{2}{*}{$* 0.001$} \\
\hline & Post-test & 3.42 & 2.78 & & \\
\hline \multirow{2}{*}{$\begin{array}{c}\text { Sleep-disordered } \\
\text { breathing }\end{array}$} & Pre-test & 4.91 & 1.03 & \multirow[t]{2}{*}{1.71} & \multirow[t]{2}{*}{0.301} \\
\hline & Post-test & 4.23 & 1.13 & & \\
\hline \multirow{2}{*}{ Sleep onset delay } & Pre-test & 2.03 & 2.11 & \multirow{2}{*}{2.72} & \multirow{2}{*}{$* 0.001$} \\
\hline & Post-test & 1.13 & 2.38 & & \\
\hline
\end{tabular}


In the combined intervention group, consisting of both endurance training and Q10 supplementation, the mean scores of total CSHQ and its eight subscales significantly reduced in the post-test (Table 3 ).

Table 3: Comparison of the mean $( \pm S D)$ pre-and pre-test scores of CSHQ in the combined intervention group

\begin{tabular}{|c|c|c|c|c|c|}
\hline Variable & Test & Mean & Standard Deviation & $\mathbf{t}$ & P-value \\
\hline \multirow{2}{*}{ Total } & Pre-test & 58 & 5.13 & \multirow{2}{*}{4.63} & \multirow{2}{*}{$* 0.001$} \\
\hline & Post-test & 43.04 & 7.01 & & \\
\hline \multirow{2}{*}{ Lack of sleep } & Pre-test & 14.23 & 3.21 & \multirow{2}{*}{3.78} & \multirow{2}{*}{$* 0.001$} \\
\hline & Post-test & 11.32 & 3.58 & & \\
\hline \multirow{2}{*}{ Bedtime resistance } & Pre-test & 10.01 & 2.25 & \multirow{2}{*}{3.46} & \multirow{2}{*}{$* 0.001$} \\
\hline & Post-test & 8.06 & 3.25 & & \\
\hline \multirow{2}{*}{ Parasomnia } & Pre-test & 11.01 & 2.96 & \multirow{2}{*}{3.08} & \multirow{2}{*}{$* 0.001$} \\
\hline & Post-test & 9.23 & 2.88 & & \\
\hline \multirow{2}{*}{ Sleep anxiety } & Pre-test & 6.12 & 3.14 & \multirow{2}{*}{2.65} & \multirow{2}{*}{$* 0.001$} \\
\hline & Post-test & 4.12 & 3.12 & & \\
\hline \multirow{2}{*}{$\begin{array}{l}\text { Inadequate sleep } \\
\text { duration }\end{array}$} & Pre-test & 4.76 & 1.12 & \multirow{2}{*}{2.89} & \multirow{2}{*}{$* 0.001$} \\
\hline & Post-test & 3.06 & 1.02 & & \\
\hline \multirow{2}{*}{ Night waking } & Pre-test & 4.97 & 2.13 & \multirow{2}{*}{3.18} & \multirow{2}{*}{$* 0.001$} \\
\hline & Post-test & 3.02 & 2.11 & & \\
\hline \multirow{2}{*}{$\begin{array}{l}\text { Sleep-disordered } \\
\text { breathing }\end{array}$} & Pre-test & 4.86 & 1.12 & \multirow[t]{2}{*}{2.25} & \multirow[t]{2}{*}{$* 0.001$} \\
\hline & Post-test & 3.03 & 1.14 & & \\
\hline \multirow{2}{*}{ Sleep onset delay } & Pre-test & 1.95 & 2.00 & \multirow{2}{*}{3.59} & \multirow{2}{*}{$* 0.001$} \\
\hline & Post-test & 1.00 & 2.08 & & \\
\hline
\end{tabular}

\section{Discussion}

The present study aimed at investigating the effect of endurance training and Q10 consumption on sleep habits separately and simultaneously. In the endurance training group, except for sleep anxiety and sleep-disordered breathing, total and subscales scores of CSHQ significantly reduced in the post-test compared to the pre-test. The results of the study were consistent with those of other research [10-12] in terms of the effect of physical activity on improved sleep quality. Also, many studies reported the positive effect of physical activity on sleep quality in the population of other countries $[17,19]$.

In the Q10 supplementation group of the present study, a significant decrease was observed in the mean post-test score compared to the pre-test in all subscales, except for sleep-disordered breathing. Concerning the effects of Q10 supplementation on mitochondrial function and the body metabolism, some factors, such as resistance to blood sugar regulating drugs, strength and fatigue, migraine headaches, and urinary microalbumin, showed improvement following Q10 supplementation [14,15,17,20]. However, since no similar study is performed so far, the effect of Q10 supplementation on sleep quality was consistent with those of other research. CoQ10 is a fat-soluble antioxidant involved in the production of intracellular energy, the electron-transport chain of mitochondria, and the synthesis of ATP in the mitochondrial membrane. It prevents membrane lipid peroxidation, stabilizes cell membranes, maintains cellular strength and function, and stimulates the immune system. Consumption of Q10 increases capillary density, reduces resistance in the lateral side artery, increases diastolic end volume, stroke volume, and heart rate, increases mitochondrial number and volume, increases lactate uptake, increases enzymes for aerobic metabolism, and subsequently, increases muscle oxygen consumption and oxygen extraction from the blood, and ultimately, cardiovascular adaptation, and improves hemodynamic indicators and the quality of life. Nevertheless, the extent of improvement in these indicators and the quality of life depends on the initial preparation of the body, age, gender, and the intensity and number of exercises [21]. It is recommended to perform further studies considering these factors on larger sample sizes. 
In the group undergoing the combined intervention (endurance training plus Q10 supplementation), the mean CSHQ score in all the subscales significantly reduced in the post-test than in the pre-test, showing the synergistic effect of synchronizing endurance training and Q10 supplementation on sleep quality.

The study results suggest the role of physical activity and Q10 supplementation in improving sleep quality in children with ASD. The results are important since no similar study evaluating the effect of both interventions (endurance training and Q10 supplementation) on the sleep quality is performed thus far; on the other hand, studies in this area are more descriptivecorrelational with large sample sizes and, therefore, the difference between the present study and other ones is the evaluation of the sleep quality in children with ASD, but considering the small sample size of the present study and differences in the subjects' physical status and the need of following up their physical and even mental status, the obtained results can only be generalizable if further studies with larger sample sizes are conducted. Finally, the results suggest that to improve the sleep quality of children with ASD, a problematic factor for such patients, various interventions, such as increased physical activity and appropriate supplementation (CoQ10), might be fruitful; the point recommended by previous studies. The results of the current study confirmed the necessity of emphasizing the conduction of further studies in this area.

\section{Acknowledgements}

The results of the present study were obtained from a master's thesis in Exercise Physiology, performed at the Islamic Azad University of Zanjan (thesis code: 13821423952003), under the supervision of Dr. Farhad Safari, a nutrition physiologist. The authors wish to thank the Welfare Organization, the faculty members, and all the participants helping the conduction of the study.

\section{Conflict of interest}

The author declares no conflicts of interest.

\section{References}

1. Liu J, Yao L, Zhang W, et al. Gray matter abnormalities in pediatric autism spectrum disorder: a meta-analysis with signed differential mapping. Eur Child Adolesc Psychiatry. 2017; 26(8): 933- 45.

2. MacDonald M, Hatfield B, Twardzik E. Child Behaviors of Young Children With Autism Spectrum Disorder Across Play Settings. Adapt Phys Activ Q. 2017; 34(1): 19- 32.

3. Guo X, Duan X, Long Z, et al. Decreased amygdala functional connectivity in adolescents with autism: A resting-state fMRI study. Psychiatry Res. Neuroimaging. 2016; 257(30): 47- 56.

4. Jiujias M, Kelley E, Hall L. Restricted, Repetitive Behaviors in Autism Spectrum Disorder and Obsessive-Compulsive Disorder: A Comparative Review. Child Psychiatry Hum Dev. 2017; 48(6): 944- 59.

5. Gross C. Defective phosphoinositide metabolism in autism. J Neurosci Res. 2017; 95(5): 1161- 73 .

6. Christensen DL, Maenner MJ, Bilder D, et al. Prevalence and characteristics of autism spectrum disorder among children aged 8 years-autism and developmental disabilities monitoring network, 11 sites, United States. MMWR Surveill Summ. 2019: 68(2): 1- 19.

7. Ghaffari MA, Mousavinejad E, Riahi F, Mousavinejad M, Afsharmanesh MR. Increased Serum Levels of Tumor Necrosis Factor-Alpha, Resistin, and Visfatin in the Children with Autism Spectrum Disorders: A Case-Control Study. Neurol Res Int. 2016.

8. Masi A, DeMayo MM, Glozier N, Guastella AJ. An overview of autism spectrum disorder, heterogeneity and treatment options. Neurosci Bull. 2017; 33(2): 183- 93.

9. Zhang R, Zhang HF, Han JS, Han SP. Genes related to oxytocin and arginine-vasopressin pathways: associations with autism spectrum disorders. Neurosci Bull. 2017; 33(2): 238- 46.

10. Wachob D, Lorenzi DG. Brief Report:Influence of Physical Activity on Sleep Quality in Children with Autism. J Autism Dev Disord. 2015; 45(8): 2641- 46.

11. Must A, Phillips SM, Carol C, Bandini LG. Barriers to physical activity in children with autism spectrum disorders: Relationship to physical activity and screen time. J Phys Act Health. 2015; 12(4): 529- 34.

12. Heffernan KS, Columna L, Russo N, et al. Brief Report: physical activity, Body Mass Index 
and Arterial Stiffness in Children With Autism Spectrum Disorder: Preliminary Findings. J Autism Dev Disord. 2018; 48(2): 625- 31.

13. Gross C. Defective phosphoinositide metabolism in autism. J Neurosci Res. 2017; 95(5): 1161- 73 .

14. Akbari M, Zeinali A, Mozaffari Khosravi H, et al. The Effect of CoQ10 Supplementation on Insulin Resistance and Blood Glucose of Patients with Type Two Diabetes. Toloo-e-Behdasht. 2014; 12(4): 13- 23. [In Persian]

15. Khorvash F, Bagheri L, Ghasemi M, GhaedAmini A. Coenzyme Q10 in Migraineylaxis:A Randomize -Double-blind ,Placebo-Controlled Clinicall Trail. J Isfahan Med School. 2016; 33(358): 1904- 11. [In Persian]

16. Owens JA, Spirito A, Mcguinn M, Nobile CH. Sleep habits and sleep disturbance inelementary school- age children. J Dev Behav pediatr. 2000; 21(1): 27- 36.

17. Mohseni I, Gaeini A. The Effect of 6 Weeks Coenzyme Q10 Supplementation on Aerobic Endurance, Peak power, Minimum Power, Average Power and Fatigue Index in Football Players. J Food Technology\&Nutriation. 2014; 11(4): 33- 44.
18. Atadokht A, Mohammadi I. Effectiveness of Aerobics Exercises on Sleep Quality of Chronic Psychiatric Patients Admitted in Rehabilitation Center in Ardabil. J Rafsanjan Univ Med Sci. 2015; 14(1): 3- 14. [In Persian]

19. Sadat-Hoseini SK. Effects of rhythmic aerobic exercises on sleep quality in sedentary young women. Razi J Med Sci. 2016; 23(149): 18- 27. [In Persian]

20. Sadeghi sedeh B, Mohaghegh P, khosro Beki A, et al. Prophylactic effects of Q10 capsule on proteinuria in diabetic patients. Revista Latinoamericana de Hipertensión. 2018; 3(13): 291- 96.

21. Esteki S, Ebrahim kh, Gholami M, Jalalian R. The effect of coenzyme Q10 and exercise training on some indicators of the hemodynamicfor patients with heart failure. Med J Mashhad. 2018; 61(2): 950- 57. [In Persian] 